\title{
Ontogeny repeats phylogeny in Steatoda and Latrodectus spiders
}

Author(s): Gilbert Barrantes and William G. Eberhard

Source: Journal of Arachnology, 38(3):485-494. 2010.

Published By: American Arachnological Society

DOI: $10.1636 / \mathrm{B} 10-05.1$

URL: http://www.bioone.org/doi/full/10.1636/B10-05.1

BioOne (www.bioone.org) is an electronic aggregator of bioscience research content, and the online home to over 160 journals and books published by not-for-profit societies, associations, museums, institutions, and presses.

Your use of this PDF, the BioOne Web site, and all posted and associated content indicates your acceptance of BioOne's Terms of Use, available at www.bioone.org/page/terms_of_use.

Usage of BioOne content is strictly limited to personal, educational, and non-commercial use. Commercial inquiries or rights and permissions requests should be directed to the individual publisher as copyright holder. 


\title{
Ontogeny repeats phylogeny in Steatoda and Latrodectus spiders
}

Gilbert Barrantes: Escuela de Biología, Universidad de Costa Rica, Ciudad Universitaria Rodrigo Facio, San José, Costa Rica. E-mail: gilbert.barrantes@gmail.com

William G. Eberhard: Smithsonian Tropical Research Institute, Escuela de Biología, Ciudad Universitaria Rodrigo Facio, Universidad de Costa Rica, San Pedro, San José, Costa Rica

\begin{abstract}
Web designs of young spiders are often less derived than those of older conspecific individuals. This study tested whether this "ontogeny repeats phylogeny" pattern occurs in two species of Latrodectus and two species of the closely related genus Steatoda. This pattern was assumed to occur in a recent study of a third Latrodectus species, L. geometricus, which attempted to deduce a probable evolutionary derivation of gum-foot webs of theridiids on the basis of ontogenetic changes. We found the same basic ontogeny repeats phylogeny ontogenetic pattern in all four species, suggesting that the previous suppositions were justified. As expected, the webs of the young instars of the two Latrodectus species were more similar than those of the adults, and were more similar to those of young than to those of adults of L. geometricus. One apparently derived trait of $L$. mirabilis, attaching prey remains as camouflage for the spider in the central portion of the web, did not change during ontogeny, and was present in even the webs of first-instar spiderlings. Field observations of $L$. mirabilis suggest that the ontogenetic change from light to darker abdominal color patterns that occurs in many Latrodectus species may result from changes in selection for camouflage associated with ontogenetic changes in web designs and the spiders' resting sites. The webs of Steatoda also fit the ontogenetic pattern: at least some ontogenetic changes in both species involved younger spiders having less derived traits than those of adults. The webs of young Steatoda spiders were more derived in some respects than those of the early instars of Latrodectus.
\end{abstract}

Keywords: Web design, ontogenetic pattern, plesiomorphic traits, web evolution

Morphological parallelism between ontogeny and phylogeny in numerous organisms seems to support the Biogenetic Law, which states that ontogenetic stages of a descendant tend to trace the phylogenetic history of adult ancestors (Eldredge and Cracraft 1980, review in Richardson and Keuck 2002). Similar patterns in behavioral features are scarce (Rial et al. 1993; Wenzel 1993). However, ontogenetic changes in the designs of spider webs are well known to show a "biogenetic" pattern in which the designs of the webs of younger individuals of a species tend to be more plesiomorphic than those of older individuals in those species in which web design changes as spiders mature. This pattern has been observed in 13 different web-building spider genera with different web designs (summaries in Eberhard 1990; Eberhard et al. 2008a; Kuntner et al. 2008, 2010). It is not clear why this pattern should occur, but it is so consistent that it was used "in reverse" in a recent study of the theridiid Latrodectus geometricus C.L. Koch 1841 to deduce the probable ancestral web form for theridiids on the basis of ontogenetic changes. This led to a reconstruction of the possible sequence of events leading to the abandonment of the ancestral orb web design in the evolutionary line of theridiids (Eberhard et al. 2008a). The webs of early-instar $L$. geometricus nymphs (but not those of the adults) have a clear radial organization of lines in the central area of the web, and the more or less regularly spaced lines bearing sticky silk are attached to these radial lines. In addition, the interior of the dense, central "disc" where the radial lines converge sometimes has a radial organization. Eberhard et al. (2008a) argued that these radial lines may be homologous to the radial and hub lines in orb webs, and that some details of the behavior used by L. geometricus to build radial and gumfoot lines may be homologous with traits associated with radius and sticky spiral construction of aranoid orb-weavers.
The present study asks whether this admittedly ambitious use of the ontogeny repeats phylogeny pattern of behavior was justified. We studied ontogenetic changes in the web designs of four additional species related to L. geometricus, two in the genus Latrodectus and two in its sister genus Steatoda (Agnarsson 2004). Using largely qualitative data, we asked two questions. Do the webs of younger individuals resemble more closely those of first-instar L. geometricus than they do those of older individuals of this species, as would be expected from previous studies? And do these ontogenetic differences involve younger spiders making more ancestral web designs?

The genera Latrodectus and Steatoda are part of a monophyletic line thought to have branched early from the rest of Theridiidae (Agnarsson 2004; Arnedo et al. 2004). Within the genus Latrodectus, L. mirabilis (Holmberg 1876) and L. hesperus Chamberlin and Ivie 1935 are part of one branch of the most basal bifurcation, while geometricus is in the other branch (Garb et al. 2003).

\section{METHODS}

Egg sacs of L. mirabilis were found associated with mature females collected on 12 December 2008 at Piedras de Afilar, Canelones, Uruguay $\left(34^{\circ} 45^{\prime} \mathrm{S}, 55^{\circ} 33^{\prime} \mathrm{W}\right)$; one egg sac of $L$. hesperus (?) was collected in January 2009 in the Sonoran desert near Phoenix, Arizona, USA, from a web in which the female was inaccessible. Egg sacs were obtained from mature females of Steatoda nr. hespera Chamberlin \& Ivie 1933 collected in December 2008 on Cerro San Bernardo at the northern edge of Salta, Argentina, and from S. grossa (C.L. Koch 1838) collected indoors in December in Montevideo, Uruguay. Unless stated otherwise, the descriptions below of webs of first-instar spiders refer to the first web built by the spiderling after it was removed from the cluster of individuals following its emergence from the 
egg sac. We use the terms "nymph 1" and "first-instar nymphs" interchangeably to refer to the nymphal stage that emerges from the egg sac and builds a web (Foelix 1996).

Specimens of $S$. nr. hespera were identified by Ingi Agnarsson. The probable identities of $S$. grossa and Latrodectus mirabilis were deduced from the fact that they are the only species of these genera known to occur near Montevideo. Similarly, the most common species near Phoenix, Arizona is L. hesperus; nevertheless, L. mactans may also be present, and it is not possible at present to confidently identify even adults of these Latrodectus species (J. Miller pers. comm.). We thus refer to this species throughout as L. hesperus (?). Voucher specimens have been deposited in the arachnological collection of Facultad de Ciencias, Montevideo, Uruguay (L. mirabilis and $S$. grossa), in the Museo Argentino de Ciencias Naturales in Buenos Aires, Argentina ( $S$. nr. hespera), and in the Museo de Zoología of the Universidad de Costa Rica (all species).

Spiders whose webs were to be photographed were placed in rectangular cardboard frames that were wrapped in fresh selfadhesive plastic wrapping material, to which the spiders almost never attached their lines. The dimensions of the frames varied with the size of the spider, from $8-10 \times 6 \times 5 \mathrm{~cm}$ for first-instar nymphs to $14 \times 12 \times 10 \mathrm{~cm}$ for adult female $S$. nr. hespera, S. grossa, and L. hesperus (?). Frame sizes for intermediate instar and adult L. mirabilis $(12 \times 12 \times 14 \mathrm{~cm})$ were based on dimensions of webs observed in the field. Webs were photographed before and after being coated with either talcum powder (early instars) or cornstarch (later instars and adults) (the finer grains of talcum powder provided better resolution of lines). In no case did we photograph or take data from more than one web of a given individual in any given instar. We attempted to mimic field conditions for some adult and first-instar $S$. nr. hespera by providing a cylindrical retreat in a sloping, moderately moist soil surface in a large container $(30 \times 16 \times 8 \mathrm{~cm}$ for adults, a $8 \mathrm{~cm}$ diameter plastic cup for first instars) that was lined with paper and covered above with plastic wrap. In frames for larger individuals of S. grossa and L. hesperus (?), we included as a retreat a small cardboard tube slightly larger in diameter than the spider, in an attempt to more nearly mimic field conditions.

We concentrated on describing young webs (after only 1-3 nights of construction), in which early regularities in web construction had not yet been obscured by lines added later (Eberhard 1987; Benjamin \& Zschokke 2002; Eberhard et al. 2008a). Webs were checked for the presence of masses of loose silk ("fluff") by careful searches of unpowdered webs under a dissecting microscope. The presence of sticky balls on lines was checked both by similar direct searches, and (in the case of young $S$. nr. hespera) by gently jarring lines throughout the web after powdering the web, thus removing the powder from non-sticky lines. The numbers of gumfoot lines attached to different horizontal lines were determined by searches in powdered webs under a dissecting microscope. The "length" of a horizontal line of this sort was taken to be the distance between attachments to other similar lines. The presenceabsence of a central disc and the array of horizontal lines outside and inside the disc were determined by carefully searching in powdered webs under a dissecting microscope.

We analyzed presence-absence variables using Chi-square contingency tables and Fisher exact tests. Quantitative variables, maximum number of gumfoot lines attached to a single horizontal line and total number of gumfoot lines per web were analyzed with Mann-Whitney tests ( $Z$ approximation) or Kruskal-Wallis analyses of variance $(H)$; pairwise comparisons were conducted using Mann-Whitney and Bonferroni corrections when the $H$ value was significant.

\section{RESULTS}

L. mirabilis.-Field: More than 300 webs of L. mirabilis ranging from those of $2^{\text {nd }}$ instar nymphs to adults were observed in the field (Piedras de Afilar; Fig. 1). All of the webs of nymphs had a centrally located disc-like sheet in a tangle only a few $\mathrm{cm}$ above the surface of the ground (Figs. 2-4). In all cases the central disc had one (usually many more) body of apparent prey (nearly all ants) attached to it; some also had plant detritus. The spider rested under this "roof" of corpses, where it was difficult to discern visually (Fig. 4). At least some discs had more or less horizontal lines that seemed to radiate from their edges (lines with stars in Fig. 3). There were multiple vertical lines attached to the substrate below the web in some webs (Fig. 2); some lines appeared to have sticky silk at their lower tips.

In contrast, the webs of larger individuals (estimated $5^{\text {th }}$ penultimate instars) nearly always lacked accumulations of prey in the central portion of the web, and the spider rested at the edge of the web under an overhanging object (usually a rock) (Fig. 5). Some retreats had small accumulations of prey hanging near the undersurface of the rock, while others lacked prey carcasses entirely. One had vertical lines with sticky lower tips attached to the substrate below the horizontal sheet that extended from the site where the spider rested (Fig. 6). These spiders had darker abdomens (mostly black with red markings), thus contrasting with the light colors of early instars.

Captivity: Nymphs 1-3: The webs of ten first-instar nymphs built in captivity all had a central planar area (Table 1), where non-sticky, more or less horizontal lines with a distinct radial pattern converged (Figs. 7,8). In eight of the webs this central area had a distinct disc-like sheet of more tightly meshed, nonsticky lines and in its interior also had lines with an at least vaguely radial organization (Figs. 7, 8). All webs had many (median 20, range 9-46) vertical or nearly vertical gumfoot lines attached below to the frame, each with a small sticky section about $1 \mathrm{~mm}$ long at its lower end. These were the only sticky lines seen in the web. The gumfoot lines were attached above to a more or less horizontal radial line, usually with a small white speck (fluff mass) at or near this attachment. These horizontal lines often had multiple, more or less regularly spaced vertical lines attached to them (median 3, range 2-5) (Fig. 7). None of the spiderlings had a retreat, and all remained at the central disc (Table 1). First-instar spiderlings fastened the remains of the first prey they captured close together at the central disc, thus producing small versions of the roof structures seen in the field.

Captivity: Late instar female nymphs and adult females: Nine webs (three of late juveniles and six of adult females) differed from those of first-instar nymphs in having a more clearly defined, domed, more or less horizontal sheet of nonsticky lines rather than a central disc, and in lacking a clear radial organization of lines in or around the sheet (Tables 1, 


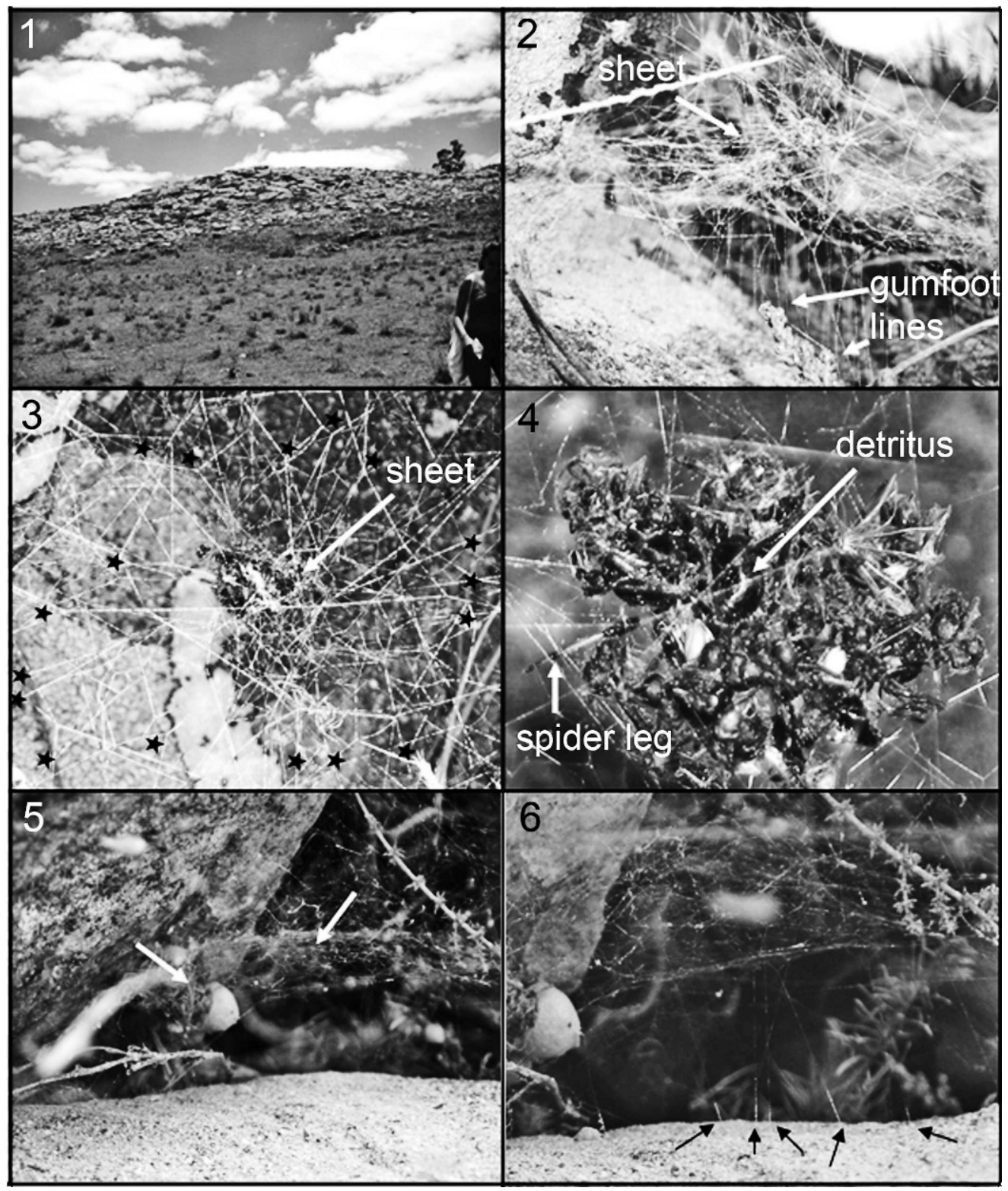

Figures 1-6.- Habitat and web traits in the field of late-instar Latrodectus mirabilis. 1. Outcrop of large rocks where different-instar L. mirabilis were very abundant. Spiders were most abundant near the crest of this hill. 2. Lateral view of nearly vertical gumfoot lines in a late instar web. 3. Approximately horizontal lines (black stars) converging at the center of the sheet (disc). 4. Close up of prey carcasses (mostly ants) attached to the center of the web under which the spider rests. 5. Spider retreat under an overhanging rock. An egg sac (spherical structure) indicates the site where the spider rests. 6. Sticky lower tips of gumfoot lines.

2). They also lacked the approximately horizontal lines from which multiple vertical gumfoot lines ran to the substrate below. All webs had multiple gumfoot lines attached to the substrate below, with a $1-3 \mathrm{~mm}$ portion at the very tip covered with sticky balls; no other sticky lines were seen in these webs. Webs of late juveniles and adults lacked silk retreats. All included an accumulation of prey remains in the central portion of the sheet, but they were scattered rather in a tight group as in younger spiders.

L. hesperus (?).-Captivity: Nymph 1: The first webs of 23 first-instar spiderlings built in captivity were qualitatively indistinguishable from the webs of first-intar L. geometricus (Eberhard et al. 2008a: Table 1). They all had a small, central, more or less horizontal disc where the spider rested. In most cases (20 of 23), the horizontal lines that surrounded the disc had an approximately radial arrangement converging on the disc (Figs. 9, 10). All webs had approximately vertical gumfoot lines, which were attached to the floor of the frame and had balls of adhesive silk on the bottom $2-3 \mathrm{~mm}$. No other lines in the web were sticky. Usually each gumfoot line had a small mass of fluff near its upper end where it was attached to the horizontal lines (arrows in Fig. 10). The fluff masses were presumably the reeled-up remains of the line that was removed as part of "cut and reel" behavior during the construction of the gumfoot lines (Eberhard et al. 2008a). The total number of gumfoot lines (median 30, range 6-45, $n=23$ 
Table 1.-Comparisons of web traits of early juveniles and adults of five Theridiidae species: Latrodectus mirabilis (Lm), L. hesperus (Lh), L. geometricus $(\mathrm{Lg})$ (Eberhard et al. 2008a), Steatoda nr. hespera $(\mathrm{Sh})$, and S. grossa $(\mathrm{Sg})$. (- trait absent in webs; ? trait not recorded in webs).

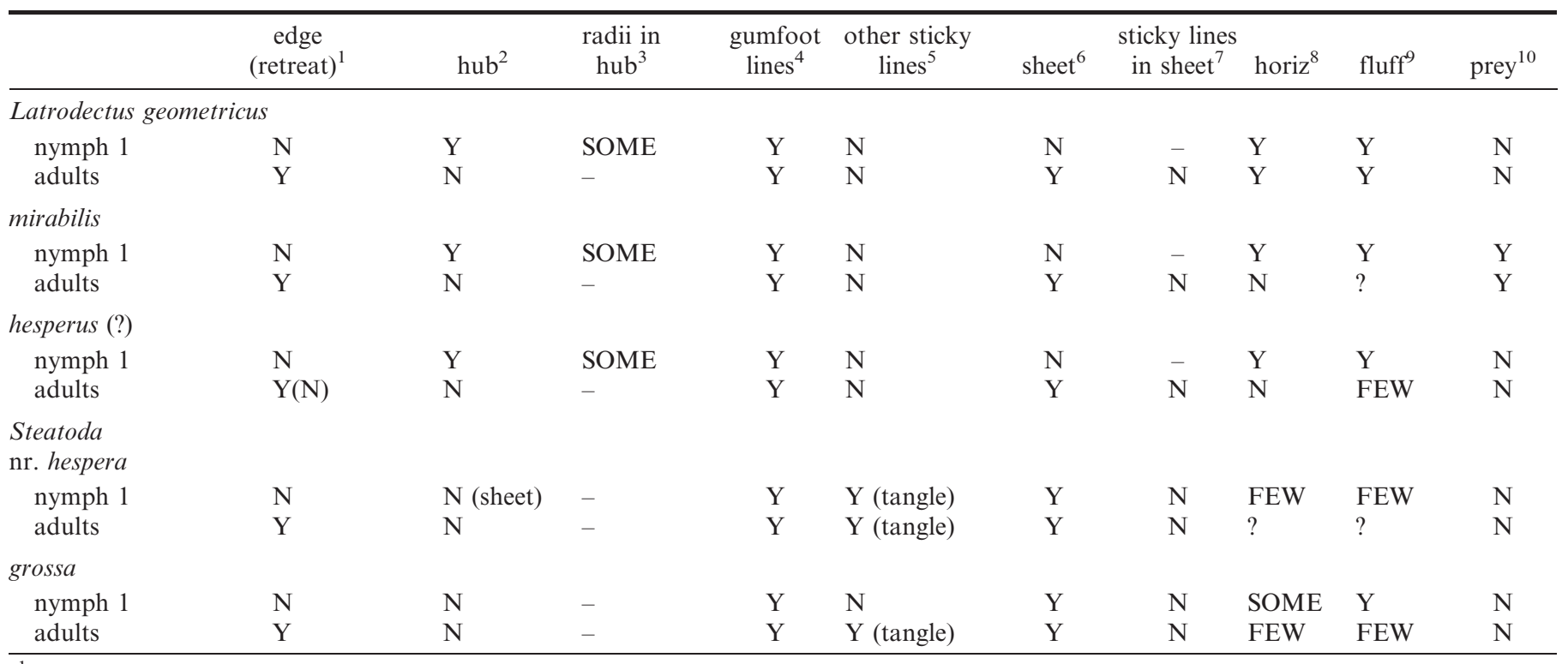

${ }^{1}$ Spider resting at edge of web (distinct silk structure built in which it rests).

${ }^{2}$ More or less radial lines converging at central point ("hub" or disc) in midst of web.

${ }^{3}$ Perceptible radial organization of lines inside "hub".

${ }^{4}$ Gumfoot lines, which have relatively short segment coated with sticky material very near the tip where line is attached to substrate.

${ }^{5}$ Sticky material on other lines in web beside gumfoot lines.

${ }^{6}$ Discernable more or less horizontal sheet.

${ }^{7}$ Sheet including some sticky lines.

${ }^{8}$ Most gumfoot lines attached at top to a more or less horizontal line to which at least one other gumfoot line is attached.

9 Top end of gumfoot line with small white mass of loose silk ("fluff").

${ }^{10}$ Prey carcasses attached to sheet. Spider generally rests under them where it is at least partly hidden.

webs) was lower than in L. geometricus webs (median 38, range $31-47, n=14$ webs; $H=23.17, P=0.00012$; Table 2). The lines within the central disc were only seldom (3 of 23) recognizably radial in orientation. Three webs had more than one disc (two with two, one with three), and in one web the single disc was elongate rather than circular. First-instar $L$. hesperus (?) spiderlings never attached their prey to the central disc (Table 2).

Captivity: Mature females: Nine adult females built webs in captivity. Six spiders occupied the tunnel in the frame; the other three rested in an upper corner of the frame but did not build a silk retreat at the resting place. None of the webs of adult females had any indication of the radial organization seen in the webs of first-instar nymphs. All nine webs had a sheet in the upper portion of the frame that varied in density from sketchy to moderately dense; the sheet slanted slightly downward from either the upper edge of the tunnel (Figs. 11, 12) or the resting place. Relatively straight "signal lines" ran to the near edge of the sheet from the upper edge of the tunnel or from the resting place of those spiders that did not rest in

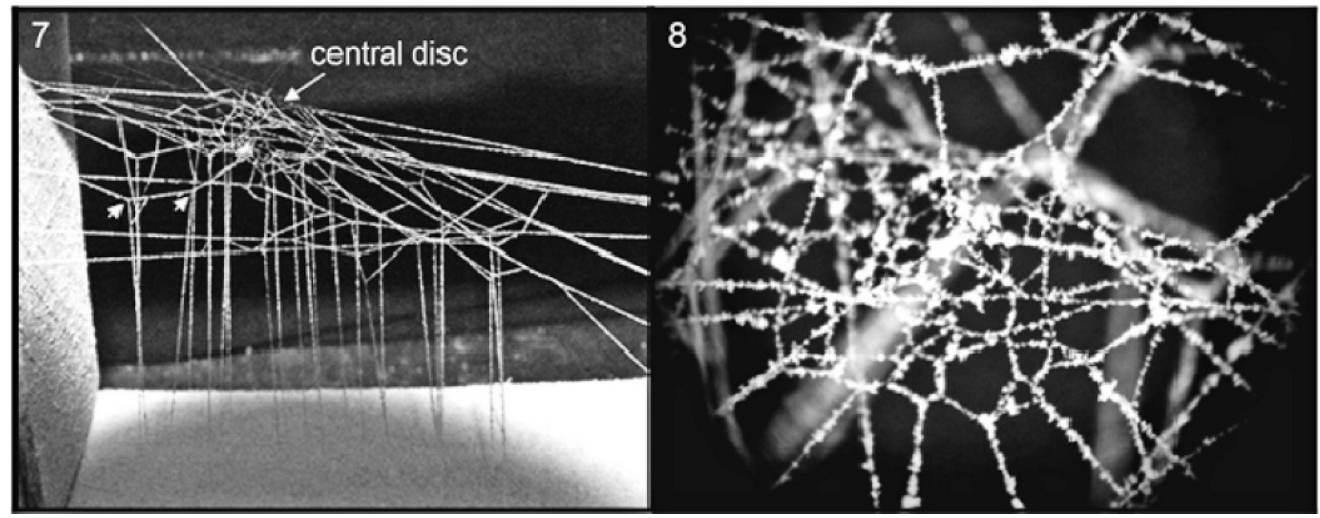

Figures 7-8.- Characteristics of first-instar nymph of Latrodectus mirabilis. 7. Complete web of a first-instar nymph; arrows show two gumfoot lines attached to a single horizontal line. 8. Dorso-lateral view of the central disc under a dissecting microscope, showing the converging, approximately horizontal lines. 
Table 2.-Quantitative comparison of web characteristics between first-instar nymphs (i1) and adult females of five Theridiidae species: Latrodectus mirabilis (Lm), L. hesperus (Lh), L. geometricus (Lg) (Eberhard et al. 2008a), Steatoda nr. hespera (Sh), and S. grossa (Sg). Same letters above species indicate statistical differences. Variables are defined in Table 1. (NA- not possible to apply a statistic test; $\varnothing$ - no data available for the corresponding group).

\begin{tabular}{|c|c|c|c|c|c|}
\hline Variable & Groups compared & Comparison & Values compared & Test & $P$ \\
\hline \multirow{5}{*}{ Retreat } & i1/ad (Lh) & Yes-No & $0 / 23,6 / 9$ & Fisher Exact & 0.0001 \\
\hline & i1/ad (Lg) & Yes-No & $0 / 15,14 / 14$ & Fisher Exact & $<0.00001$ \\
\hline & i1/ad (Sg) & Yes-No & $0 / 11,10 / 11$ & Fisher Exact & $<0.00001$ \\
\hline & i1: Lm, Lh, Lg, Sh, Sg & Yes-No & $0 / 10,0 / 23,0 / 15,0 / 14,0 / 11$ & NA & \\
\hline & ad: $\mathrm{Lm}, \mathrm{Lh}, \mathrm{Lg}, \mathrm{Sh}, \mathrm{Sg}$ & Yes-No & $0 / 9,6 / 9,14 / 14,6 / 9,10 / 11$ & $X_{(4)}^{2}=28.96$ & $<0.00001$ \\
\hline \multirow{5}{*}{ Circular disc } & il/ad (Lg) & Yes-No & $15 / 15,0 / 14$ & Fisher Exact & 0.0001 \\
\hline & il/ad (Sh) & Yes-No & $0 / 14,0 / 9$ & NA & \\
\hline & il/ad $(\mathrm{Sg})$ & Yes-No & $0 / 11,0 / 11$ & NA & \\
\hline & i1: Lm, Lh, Lg, Sh, Sg & Yes-No & $10 / 10,23 / 23,15 / 15,0 / 14,0 / 11$ & $X_{(4)}^{2}=73.00$ & $<0.00001$ \\
\hline & ad: $\mathrm{Lm}, \mathrm{Lh}, \mathrm{Lg}, \mathrm{Sh}, \mathrm{Sg}$ & Yes-No & $0 / 9,0 / 9,0 / 14,0 / 9,0 / 11$ & $\mathrm{NA}$ & \\
\hline \multirow[t]{3}{*}{ Sheet } & i1/ad (Lm) & Yes-No & $0 / 10,9 / 9$ & Fisher Exact & 0.0001 \\
\hline & i1: Lm, Lh, Lg, Sh, Sg & Yes-No & $0 / 10,0 / 23,0 / 15,14 / 14,11 / 11$ & $X_{(4)}^{2}=73.00$ & $<0.00001$ \\
\hline & ad: Lm, Lh, Lg, Sh, Sg & Yes-No & $9 / 9,9 / 9,14 / 14,9 / 9,11 / 11$ & $\mathrm{NA}$ & \\
\hline \multirow{7}{*}{$\begin{array}{l}\text { Radial organization } \\
\text { outside disc }\end{array}$} & il/ad (Lm) & Yes-No & $8 / 10,0 / 9$ & Fisher Exact & 0.0007 \\
\hline & il/ad (Lh) & Yes-No & $19 / 23,0 / 9$ & Fisher Exact & $<0.00001$ \\
\hline & i1/ad (Lg) & Yes-No & $15 / 15,0 / 14$ & Fisher Exact & $<0.00001$ \\
\hline & i1/ad (Sh) & Yes-No & $2 / 14,0 / 9$ & Fisher Exact & 0.50 \\
\hline & i1/ad (Sg) & Yes-No & $0 / 11,0 / 11$ & NA & \\
\hline & i1: Lm, Lh, Lg, Sh, Sg & Yes-No & $8 / 10,19 / 23,15 / 15,2 / 14,0 / 11$ & $X_{(4)}^{2}=45.36$ & $<0.00001$ \\
\hline & ad: Lm, Lh, Lg, Sh, Sg & Yes-No & $0 / 9,0 / 9,0 / 14,0 / 9,0 / 11$ & $\mathrm{NA}$ & \\
\hline \multirow[t]{4}{*}{ Radii inside hub } & il/ad (Lm) & Yes-No & $8 / 10,0 / 9$ & Fisher Exact & 0.0007 \\
\hline & il/ad (Lh) & Yes-No & $3 / 23,0 / 9$ & Fisher Exact & 0.99 \\
\hline & i1/ad (Lg) & Yes-No & $8 / 15,0 / 14$ & Fisher Exact & 0.0022 \\
\hline & i1/ad (Sh) & Yes-No & $0 / 14,0 / 9$ & NA & \\
\hline \multirow{2}{*}{ Other sticky lines } & i1: Lm, Lh, Lg, Sh, Sg & Yes-No & $0 / 10,0 / 23,0 / 15,7 / 8,0 / 11$ & $X_{(4)}^{2}=57.65$ & $<0.00001$ \\
\hline & ad: Lh, Lg, Sh, Sg & Yes-No & $8 / 9,0 / 14,3 / 3,11 / 11$ & $X_{(3)}^{2}=33.31$ & $<0.00001$ \\
\hline \multirow{7}{*}{$\begin{array}{l}\text { Max. no. of } \\
\text { gumfoot lines/ } \\
\text { horizontal line }\end{array}$} & i1/ad $(\mathrm{Lm})$ & Medians (range) & $3(2-5), \varnothing$ & $\mathrm{NA}$ & \\
\hline & il/ad (Lh) & Medians (range) & $4(2-9), 1(1-2)$ & $Z_{(23,9)}=4.31$ & 0.00002 \\
\hline & i1/ad (Lg) & Medians (range) & $5(3-6), 2(1-2)$ & $Z_{(14,14)}=3.97$ & 0.00007 \\
\hline & i1/ad (Sh) & Medians (range) & $2(2-2), \varnothing$ & NA & \\
\hline & i1/ad $(\mathrm{Sg})$ & Medians (range & $2(2-5), 1(1-2)$ & $Z_{(11,11)}=3.58$ & 0.00034 \\
\hline & $\begin{array}{l}\text { i1: } \operatorname{Lm}^{\mathrm{a}}, \operatorname{Lh}^{\mathrm{a}, \mathrm{b}}, \mathrm{Lg}^{\mathrm{a}, \mathrm{c}} \\
\mathrm{Sh}^{\mathrm{a}, \mathrm{b}, \mathrm{c}, \mathrm{d}}, \mathrm{Sg}^{\mathrm{b}, \mathrm{c}, \mathrm{d}}\end{array}$ & Medians (range) & $\begin{array}{l}3(2-5), 4(2-9), 5(3-6), 2(2-2), \\
\quad 2(2-5)\end{array}$ & $H=35.69$ & $<0.00001$ \\
\hline & ad: $\mathrm{Lh}, \mathrm{Lg}, \mathrm{Sg}$ & Medians (range) & $1(1-2), 2(1-2), 1(1-2)$ & $H=4.88$ & 0.09 \\
\hline & i1/ad (Lm) & Medians (range) & $20(9-46), \varnothing$ & NA & \\
\hline \multirow[t]{6}{*}{ lines/web } & i1/ad (Lh) & Medians (range) & $30(6-45), 28(9-43)$ & $Z_{(23,9)}=0.63$ & 0.53 \\
\hline & i1/ad (Lg) & Medians (range) & $38(31-47), 23(12-34)$ & $Z_{(12,14)}=3.50$ & 0.00047 \\
\hline & i1/ad (Sh) & Medians (range) & $14(8-30), \varnothing$ & NA & \\
\hline & i1/ad $(\mathrm{Sg})$ & Medians (range) & $26(10-36), 8(2-23)$ & $Z_{(11,11)}=3.59$ & 0.00014 \\
\hline & $\begin{array}{l}\text { i1: } \mathrm{Lm}^{\mathrm{a}}, \mathrm{Lh}^{\mathrm{b}}, \mathrm{Lg}^{\mathrm{a}, \mathrm{b}, \mathrm{c}} \\
\mathrm{Sh}^{\mathrm{b}, \mathrm{c}} \mathrm{Sg}^{\mathrm{c}}\end{array}$ & Medians (range) & $\begin{array}{l}20(9-46), 30(6-45), 38(31-47) \\
\quad 14(8-30), 26(10-36)\end{array}$ & $H=23.17$ & 0.00012 \\
\hline & ad: $\mathrm{Lh}^{\mathrm{a}}, \mathrm{Lg}^{\mathrm{b}}, \mathrm{Sg}^{\mathrm{a}, \mathrm{b}}$ & Medians (range) & $28(9-43), 23(12-34), 8(2-23)$ & $H=17.31$ & 0.00017 \\
\hline
\end{tabular}




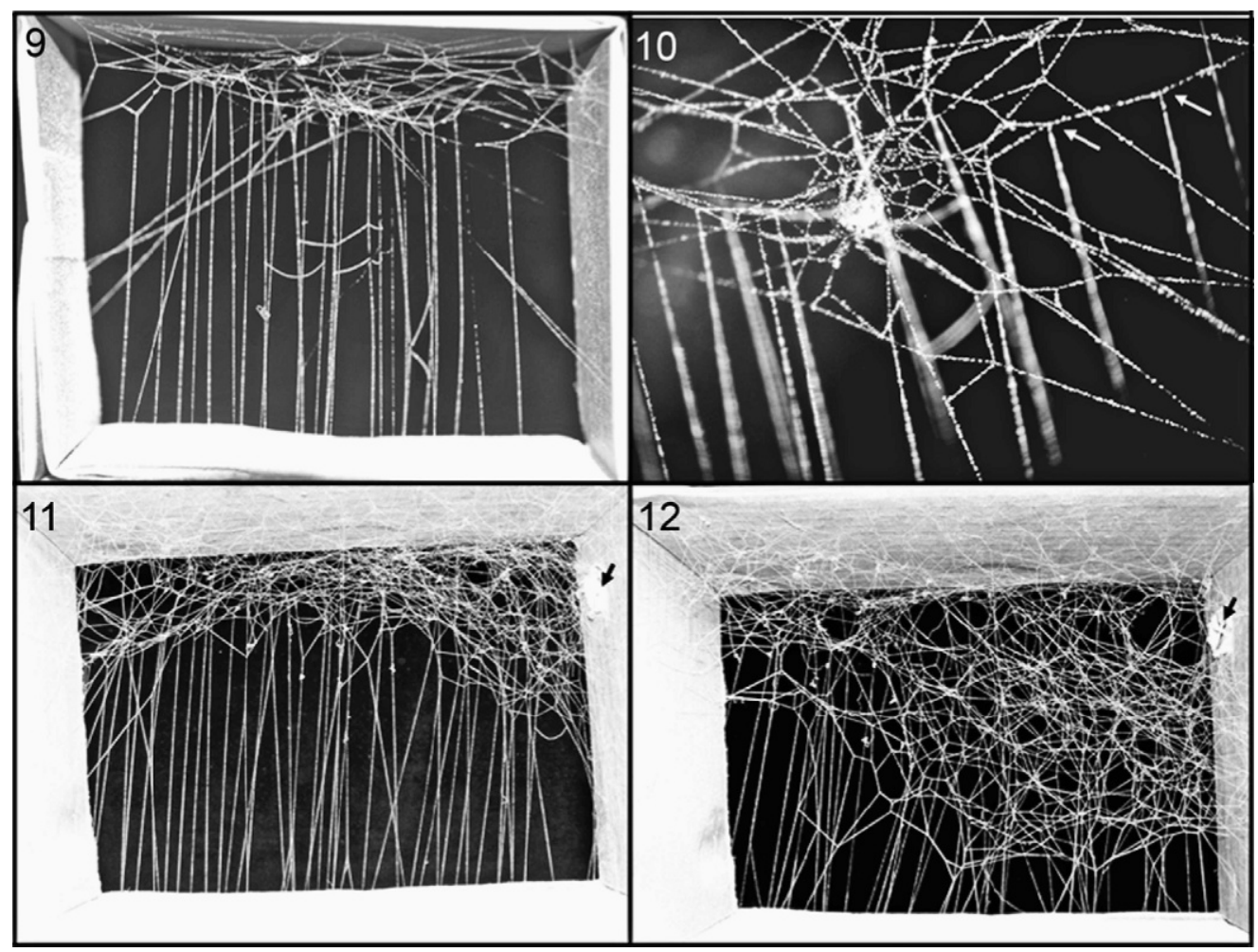

Figures 9-12.-First- and adult-instar webs of Latrodectus hesperus (?) 9. First-instar web with a small central disc. 10. Close up view of the central disc under a dissecting microscope, showing some approximately horizontal lines and two gumfoot lines attached to a single horizontal line (white arrows). 11. Adult web with slanted long sheet and relatively small lower tangle; black arrow pointing to the tunnel retreat. 12. Adult web with an extended lower tangle; black arrow pointing to the tunnel retreat.

tunnels. A sparse tangle above the sheet was attached to the upper side of the cardboard frame. Six of the webs had a dense tangle below the sheet (Fig. 12), but in the other three webs this tangle was nearly absent. Short segments of threads of the tangle were coated with adhesive balls in eight webs. Numerous nearly vertical gumfoot lines ran from the periphery of the sheet to the frame floor (median 28, range $9-43, n=9$ webs), leaving an empty space just under the central portion of the sheet. Most gumfoot lines were attached individually at the top to threads in the sheet, or to a tangle line rather than to a horizontal line at the periphery of the sheet; only one web had two gumfoot lines attached to the same line. The sticky segment of these lines extended from nearly the bottom tip up to $10 \mathrm{~mm}(8.5 \pm 1.8 \mathrm{~mm}, n=3)$. Masses of silk fluff were only seldom seen near the upper ends of gumfoot lines. In some webs fluff may have been concealed by the dense tangle, but careful checks showed that the upper ends of many gumfoot lines lacked fluff masses. No prey remains were incorporated into webs.

Steatoda nr. hespera: Field: Four webs of mature female $S$. nr. hespera were found in the field near the ground on the steep slope of second-growth forest. Each spider rested in an approximately $8 \mathrm{~mm}$ diameter tunnel at the uphill edge of the web. A sparse, more or less horizontal sheet extended from the tunnel on the downhill side. Poor viewing conditions precluded determination of whether there were lines above and below the sheet.

Two mature females that were provided with a similar situation in captivity (a tunnel in a sloping bank of earth) built apparently similar webs (Fig. 13). The web had a moderately dense, horizontal sheet of irregularly oriented, non-sticky lines under which the spider moved very rapidly to chase and attack prey that were on the sheet and also on the ground below (they quickly wrapped and reeled in these prey, lifting them off the ground). Numerous lines laid near the soil (lines accumulated over many nights) had balls of glue that were visible when in a humid environment (Fig. 14); no clear pattern in the placement of these lines was discerned. Prey that had been consumed were dropped to the ground.

Captivity: Nymph 1: We photographed the first webs of 14 first-instar nymphs of $S$. nr. hespera, five after only a single night and nine after two nights in the frame. Web designs differed substantially in details, but they all shared several characteristics. All had at least some more or less vertical gumfoot lines (median 14, range 8-30; Fig. 15), and had an approximately horizontal, often elongate sheet of non-sticky silk. The spider rested on the sheet or at the edge of the web, but in no case did it build a silk retreat. There were at least some additional tangle lines above and below the sheet, but there was a space immediately below the sheet, thus giving the spider room to move freely. In only two cases did the lines around the edges of the sheet have a perceptible radial organization, but in no case did lines in the sheet have a perceptible radial pattern.

Several other traits varied. Only the tip of the line was covered with glue in most gumfoot lines, but some lines had glue along a substantial fraction of the line, and often lines attached to the frame floor had more than one sticky segment. 


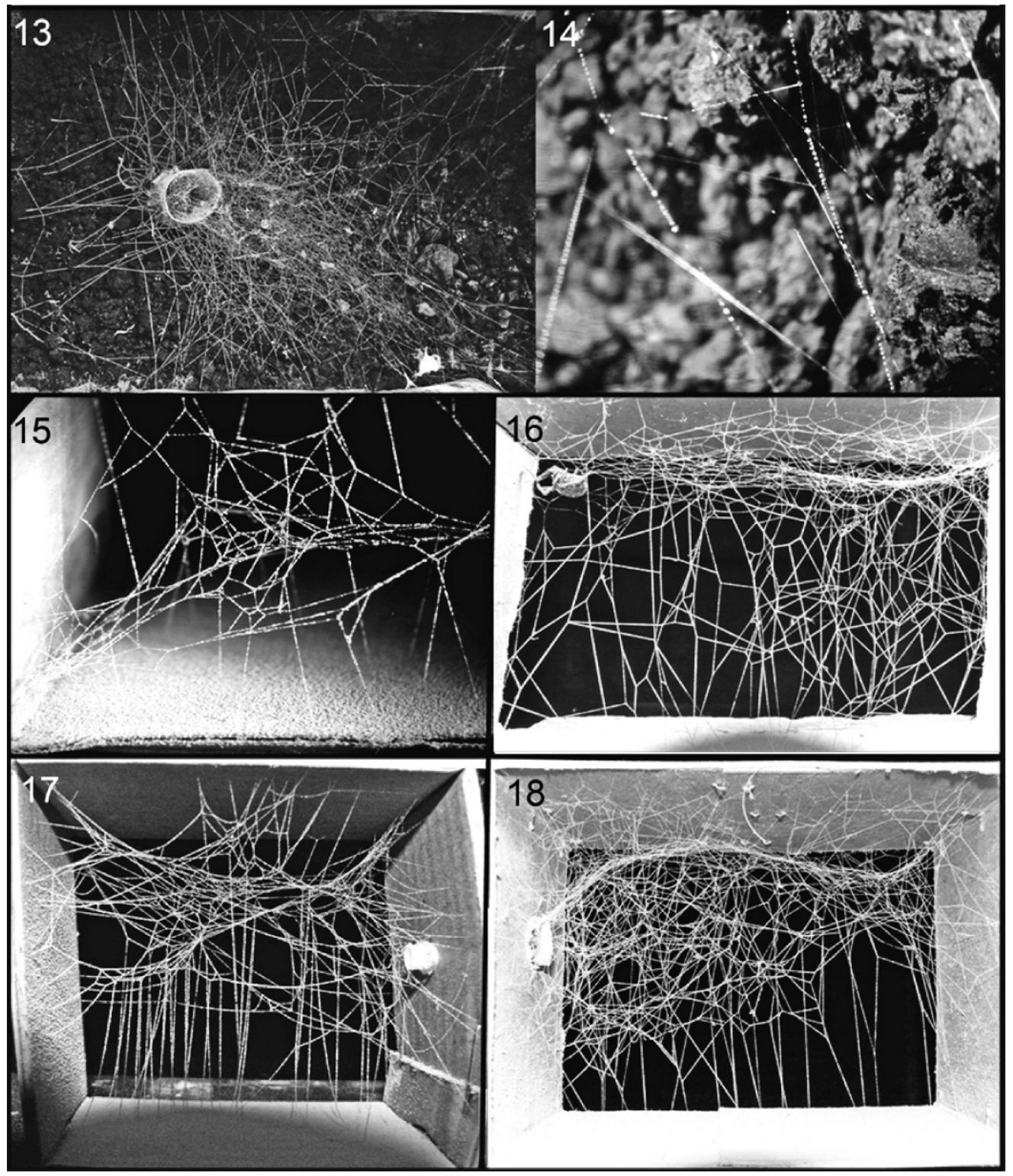

Figures 13-18.-Webs of Steatoda species. 13. Web of mature female Steatoda nr. hespera built in conditions mimicking those in the field. 14. Closeup view of early lines near the surface of the ground in a humid atmosphere, showing sticky balls on some but not other lines. 15. Web of first-instar nymph $S$. nr. hespera showing multiple gumfoot lines and a sparse sheet. 16. Web of mature female $S$. nr. hespera with a dense sheet built after three nights on a frame. 17. Web of first-instar nymph $S$. grossa with multiple gumfoot lines and relatively dense sheet. Nymph did not build a retreat inside the tunnel. 18. Web of mature female $S$. grossa showing a dense approximately domed sheet and its retreat inside the cardboard tunnel.

In most webs, gumfoot lines varied from nearly vertical to those that made much smaller angles (Fig. 15), and three webs had additional gumfoot lines running to the side of the frame. Gumfoot lines were generally attached individually to a more or less horizontal line in the tangle at the edge of the sheet; in only two webs were more than a single gumfoot line attached to the same horizontal line (Table 2). Most gumfoot lines lacked small accumulations of fluff at their upper ends. At least in seven of eight webs (in which this detail was checked) lines in the tangle (either above or below the central sheet) had stretches of glue on them. Prey remains were not incorporated in the web.
Captivity: Mature females: Three mature $S$. nr. hespera females built webs in frames that had an extensive sheet composed of irregularly oriented, non-sticky lines (Fig. 16). The sheet of one web was close to the top of the frame, while in the other two there was a loose tangle of lines above it. Two also had a loose tangle of lines below the sheet. Some lines in the tangle (above and below the sheet) were coated with sticky balls at several sites. Gumfoot lines were attached at their upper ends to a non-sticky line in the loose tangle below the sheet; others were attached to more or less horizontal sticky lines of the tangle. Some gumfoot lines had glue only near their lower tips, but in the rest the line was coated along nearly 
its entire length with sticky balls (mean $=19.7, \mathrm{SD}=3.1, n=$ $3)$, except for a few $\mathrm{mm}(2-3 \mathrm{~mm})$ at its very lower tip.

One of these females was observed building vertical sticky lines. Lines were not laid in bursts, but the spider returned to the retreat after attaching each line to the floor of the frame. In addition, it was clear that the spider did not cut and reel as it ascended after attaching one of these lines.

Steatoda grossa: Captivity: Nymph 1: Webs of 11 first-instar nymphs were photographed and examined. Nine webs had an upward sloping narrow sheet; the other two had a central, elongated disc. All webs had numerous vertical gumfoot lines (Table 2, Fig. 17), each with a short segment coated with sticky balls at its lower end where it was attached to the floor of the frame. The upper ends of most gumfoot lines were attached individually to short, more or less horizontal lines near the edge of the sheet (Table 2). In 62 of 85 gumfoot lines there was a discernible mass of fluff at or near this attachment. No other sticky lines were seen. There was no silk retreat where the spider rested in a corner of the cardboard frame at the top edge of the web. Nor was there any sign of radial organization within this sheet (or disc) or the lines around its margins (Tables 1, 2). Prey remains were not incorporated in the web.

Captivity: Adult females: The webs of ten females all lacked any indication of radial organization. Instead they had a dense, arch-shaped sheet composed of irregularly oriented non-sticky lines that ascended from the roof of the tunnelretreat opening toward the top of the frame near the center and then descended toward the opposite side of the frame (Fig. 18). Dense tangles were present above and below the sheet in all webs. Lines of the tangle below were attached to the edge of the sheet, and the spider moved freely under the central portion of the sheet. In nine of the 10 webs short segments of some threads in the upper tangle were coated with sticky material; the other web had sticky segments in the tangle below the sheet. These lines with sticky segments were attached to other dry threads in the tangle with no apparent order or orientation. The number of gumfoot lines varied widely (median $=8$, range $2-23, n=10$ ) and had sticky material covering up to the distal $17 \mathrm{~mm}$ (mean $=13.1 \pm$ $2.5 \mathrm{~mm}, n=9$ lines). Most gumfoot lines were short, and many deviated substantially from being vertical. They were attached at their upper ends either to threads of the lower tangle or to the edge of the sheet. In only two webs did we see two gumfoot lines attached to the same thread (one case in each web). A fluff mass at the upper end was discernable in only a few gumfoot lines. Prey remains were not incorporated into webs.

\section{DISCUSSION}

Table 1 summarizes qualitative ontogenetic changes in web design in the four species of this study and in L. geometricus, while Table 2 gives quantitative comparisons among species and developmental stages. Some patterns were relatively general. In all five species the webs of first-instar nymphs lacked a retreat, while nearly all adult webs in four species had a retreat (Tables 1,2 ). Only in L. mirabilis did adult webs in captivity lack a retreat, though the field webs of late-instar nymphs and adults had retreats under overhanging objects such as rocks. Possibly we did not provide these spiders with appropriate conditions to construct retreats in captivity.
The maximum number of gumfoot lines attached to a single horizontal line, as well as the total number of gumfoot lines per web, was higher in webs of first-instar nymphs than in conspecific adults in L. hesperus (?), L. geometricus, and $S$. grossa (Table 2) (data were not available for adult $L$. mirabilis and $S$. nr. hespera). First-instar nymphs of L. geometricus had the largest number of gumfoot lines per web (Table 2). Lines with sticky segments were present in the tangle web of firstinstar nymphs of $S$. nr. hespera and adult $S$. nr. hespera, $L$. hesperus (?), and S. grossa (Tables 1, 2).

Some other ontogenetic patterns were more restricted. Those of Latrodectus were simpler so we discuss them first. The changes in Latrodectus mirabilis and L. hesperus (?) are very similar to those of L. geometricus (Eberhard et al. 2008a). Younger individuals of all three species differed from conspecific adults in producing $a$ ) a central planar area (disc), $b$ ) more or less radial lines around the disc, $c$ ) approximately horizontal lines near the disc to which multiple gumfoot lines were attached, $d$ ) larger numbers of gumfoot lines, $e$ ) webs lacking a more or less horizontal sheet and $f$ ) webs that lacked a silk retreat at the edge of the web or a retreat inside a tunnel (the spider instead rested under the central disc). In the webs of intermediate juvenile instars the central disc gradually became extended into a more elongate sheet, and the number of gumfoot lines attached to any given approximately horizontal line became smaller, as also occurred in $L$. geometricus. Independent evidence suggests that the traits of younger spiders with respect to $e$ and $f$ are ancestral compared with those of the adults (Eberhard et al. 2008a; Szlep 1965, 1968). One aspect of the ontogeny of $L$. mirabilis differed with L. geometricus: the first-instar nymphs and all later stages fastened the corpses of prey to the central disc or sheet, providing apparent camouflage for the spider.

Within Steatoda, S. nr hespera showed three ontogenetic changes in web design (younger spiders rested centrally on the web rather than at the edge, built a larger number of gumfoot lines and failed to build a retreat); in all of these respects the behavior of younger spiders is probably more ancestral (Eberhard et al. 2008a). In S. grossa two ontogenetic changes, the addition of sticky material to other lines in addition to gumfoot lines and the use of tunnel retreats in the webs of adults, also show the same pattern, the webs of adult spiders showing more derived web traits.

In general, the ontogenetic patterns in both genera thus fit with the tendency for web ontogeny to reflect phylogenetic changes in web design. These findings support the arguments made previously in attempting to deduce how gumfoot webs evolved from orbicular ancestral webs (Eberhard et al. 2008a, 2008b). Given our generally small sample sizes and the substantial variation in some web traits, the qualitative changes may be more certain than the quantitative changes. It is interesting to note that sticky silk may be particularly valuable to these spiders, as one mature female $S$. nr. hespera spent several minutes (possibly) re-ingesting sticky silk that she had wrapped onto a prey that subsequently escaped.

Comparing Latrodectus and Steatoda, independent evidence (Eberhard et al. 2008a) suggests that young Steatoda show more derived web traits than do young Latrodectus. The three traits accentuated in Steatoda, adding sticky material to lines other than gumfoot lines, discarding gumfoot lines, and 
building a non-sticky sheet, are all thought to be more derived. The lack of gumfoot was apparent even on lines that ran more or less vertically to the substrate below in the webs of adult female $S$. nr. hespera built in cardboard frames, as they placed sticky balls not at the lower tips of these lines, but farther up away from the substrate. If the argument made previously (Eberhard et al. 2008a) that radial organization is an ancestral trait is correct, then a fourth trait, the lack of radial organization in the webs of first-instar Steatoda, is also derived.

The webs of young Steatoda resembled those of adult Latrodectus in that the lines to which gumfoot lines were attached above clearly lacked any radial organization, most of these approximately horizontal lines had only a single gumfoot line attached to them, and the web had an elongate, more or less planar sheet rather than a central disc even after only a single night of construction. In sum, the direction of change in Steatoda ontogeny was similar to that in Latrodectus (web designs of younger spiders were less derived), but the point of departure (the youngest Steatoda webs) was more derived in at least some respects than the point of departure for the Latrodectus species and was thus part way along the ontogenetic trajectory of Latrodectus species. After beginning by building webs similar to the webs of intermediate-sized Latrodectus (Eberhard et al. 2008a), Steatoda later produced webs that differed from those of any of the three Latrodectus species.

First-instar nymphs of all four species performed rapid attacks on prey, quickly reeling up the gumfoot line to which the prey had adhered and thus raising the prey rapidly from the substrate so that it was relatively helpless, then immediately wrapping it. These stereotyped and effective attacks (which in all species involved initiating wrapping with sticky silk) are well designed to function in webs with gumfoot lines (Barrantes \& Eberhard 2007) and thus also fit the idea that gumfoot webs are ancestral in this group (Eberhard et al. 2008a, 2008b).

The webs of mature female $S$. nr. hespera and S. grossa contrast sharply with those described for adults of other species of Steatoda, some of which build typical gumfoot webs with one sheet (triangulata, lepida, bipuncta) (Nielsen 1931; Lamoral 1968; Benjamin \& Zcshokke 2002) (the sheet of $S$. bimaculata may also have sticky lines - Nielsen 1931) or two horizontal sheets and a tangle above with no sticky lines $(S$. moesta) (Eberhard et al. 2008b). The common tendency for adult web forms to diverge substantially among congeneric species in Theridiidae (Eberhard et al. 2008b) thus also holds for Steatoda. The web designs of individuals of $S$. nr. hespera were also especially flexible, comparing webs in cardboard frames with webs in more natural circumstances (Figs. 13, 16). Such intraspecific variation, previously documented in Latrodectus (Lamoral 1968; Kaston 1970), but not in Steatoda, is apparently also widespread in Theridiidae (Eberhard et al. 2008b). This variation makes it necessary to be cautious in generalizing from limited observations such as those we present here.

One further general trend that seemed clear (though we did not collect standardized observations) was that in all the Latrodectus and Steatoda species, younger spiders built relatively complete webs more quickly, often during a single night, while adults added lines more slowly, over many nights. This might appear to be an exception to the ontogeny repeats phylogeny pattern, because gradual accumulation of lines is surely an ancient trait in spiders in general (Eberhard 1990). But if theridiids are descended from an orb-weaving ancestor (Agnarsson 2004; Arnedo et al. 2004), in which the entire web was presumably built in one burst of construction, then the gradual addition of lines by adult theridiids may be a secondarily derived trait.

Our observations of Steatoda differ in at least one respect from those of Benjamin \& Zschokke (2002) on S. triangulosa. There were no radially arranged lines centered on the retreat at the edge of the web, as described by Benjamin \& Zschokke (2002). They also stated that cut and reel behavior did not occur in $S$. triangulosa, while we found that in both Steatoda species at least some gumfoot lines clearly had a small white mass of fluff near the site where the gumfoot line was attached at its upper end. These masses suggest that the spider cut and then reeled up the line as it moved upward during gumfoot line construction (Eberhard et al. 2008a). Many gumfoot lines in the webs of both $S$. nr. hespera and S. grossa appeared to lack these white specks, however, and direct observation (with good viewing conditions) of the construction of one gumfoot line by an adult female of $S$. nr. hespera clearly showed a lack of cut and reel behavior. Thus cut and reel is not necessarily a part of all gumfoot line construction in Steatoda.

We cannot evaluate the possibility that gumfoot line construction in Latrodectus also occasionally occurs without cut and reel behavior. We observed some gumfoot lines lacking a mass of fluff at the upper end. However, if the cut line tangled on other web lines while it was still more or less extended and thus before it collapsed on itself in a single mass, the white speck would be reduced or eliminated. In addition, we did not successfully locate the upper ends of all gumfoot lines, perhaps because the upper end was sometimes in the middle of the tangle, so some white specks there could possibly have been missed. Thus we cannot be sure that all failures to find fluff masses were due to a lack of cut and reel behavior.

Ontogenetic changes in abdomen coloration from lighter to darker colors are apparently widespread in Latrodectus (Kaston 1970). Our field observations of L. mirabilis suggest that the ontogenetic change in abdomen color in this species is associated with changes in its web design. Younger-instar spiders had light-colored abdomens (mostly white in at least the three first instars), built webs at exposed sites and rested in the central portion of these webs. The light color of a spider with few or no prey remains would probably reduce its visibility; at the site where we observed them, the predominant abdomen color was similar to that of nearby rocks. Olderinstar nymphs and adult females had much darker abdomens (black, with fine yellow and red markings), and their webs generally had a retreat at the edge, where the spider rested in the dark under an overhanging rock. The ontogenetic change in retreats involved both the site of the retreat (in the open vs. under a rock) and the placement of prey (often substantial numbers attached in a tight mass to the retreat vs. lower numbers scattered near or below the spider's resting place and not directly above it). A similar change in abdomen color from light to dark occurs in both L. geometricus and L. hesperus (?), and free-ranging young spiders of both species also rested 
exposed in the midst of their webs during the day, while older nymphs and adults of $L$. geometricus rested in retreats at or beyond the edge of the web during the day. Further observations of immature spiders in nature will be necessary to determine whether, as predicted by our idea, younger individuals of other Latrodectus species with light-colored juveniles generally rest at more exposed sites during the day than older, darker individuals.

\section{ACKNOWLEDGMENTS}

It is a pleasure to thank Fernando Costa, Anita Aisenberg, and other members of the Etología, Ecología y Evolución lab of the Instituto de Investigaciones Biológicas Clemente Estable, as well as Carmen Viera, for hosting us and providing help and good company in collecting and housing spiders. We also thank Carmen Viera for invitations to participate in the IX Jornadas de Zoología de Uruguay, which financed our trip to Uruguay, and the Universidad de Costa Rica and the Smithsonian Tropical Research Institute for other financial support.

\section{LITERATURE CITED}

Agnarsson, I. 2004. Morphological phylogeny of cobweb spiders and their relatives (Araneae, Araneoidea, Theridiidae). Zoological Journal of the Linnean Society 141:447-626.

Arnedo, M.A., J.A. Coddington, I. Agnarsson \& R.G. Gillespie. 2004. From a comb to a tree: phylogenetic relationships of the comb-footed spiders (Araneae, Theridiidae) inferred from nuclear and mitochondrial genes. Molecular Phylogenetics and Evolution 31:225-245.

Barrantes, G. \& W.G. Eberhard. 2007. The evolution of prey wrapping behaviour in spiders. Journal of Natural History 41:1631-1658.

Benjamin, S. \& S. Zschokke. 2002. Untangling the tangle-web: web construction behavior of the comb-footed spider Steatoda triangulosa and comments on phylogenetic implications (Araneae: Theridiidae). Journal of Insect Behavior 15:791-809.

Eberhard, W.G. 1987. Construction behavior of non-orb weaving cribellate spiders and the evolutionary origin of orb webs. Bulletin of the British Arachnological Society 7:175-178.

Eberhard, W.G. 1990. Function and phylogeny of spider webs. Annual Review of Ecology and Systematics 21:341-372.
Eberhard, W.G., G. Barrantes \& R. Madrigal-Brenes. 2008a. Vestiges of an orb-weaving ancestor? The "biogenic law" and ontogenetic changes in the webs and building behavior of the black widow spider Latrodectus geometricus (Araneae: Theridiidae). Ethology Ecology and Evolution 20:211-244.

Eberhard, W.G., I. Agnarsson \& H.W. Levi. 2008b. Web forms and the phylogeny of theridiid spiders (Araneae: Theridiidae): chaos from order. Systematics and Biodiversity 6:415-475.

Eldredge, N. \& J. Cracraft. 1980. Phylogenetic Patterns and the Evolutionary Process. Columbia University Press, New York.

Foelix, R.F. 1996. Biology of Spiders. Second edition. Oxford University Press, New York.

Garb, J.E., A. Gonzalez \& R.G. Gillespie. 2003. The black widow spider genus Latrodectus (Araneae: Theridiidae): phylogeny, biogeography, and invasion history. Molecular Phylogenetics and Evolution 31:1127-1142.

Kaston, B.J. 1970. Comparative biology of American black widow spiders. Transactions of the San Diego Society of Natural History 16:33-82.

Kuntner, M., C.R. Haddad, G. Aljančič \& A. Blejec. 2008. Ecology and web allometry of Clitaetra irenae, an arbicolous African orbweaving spider. Journal of Arachnology 36:583-594.

Kuntner, M., S. Kralj-Fišer \& M. Gregorič. 2010. Ladder webs in orb-web spiders: ontogenetic and evolutionary patterns in Nephilidae. Biological Journal of the Linnean Society 99:849-866.

Lamoral, B.H. 1968. On the nest and web structure of Latrodectus in South Africa, and some observations on body colouration of Latrodectus geometricus (Araneae, Theridiidae). Annals of the Natal Museum, Pietermaritzburg 20:1-14.

Richardson, M.K. \& G. Keuck. 2002. Haeckel's ABC of evolution and development. Biological Reviews 77:495-528.

Rial, R., M.C. Nicolau, J.A. Lopez-Garcia \& H. Almirall. On the evolution of waking and sleeping. Comparative Biochemistry and Physiology 104A:189-193.

Szlep, R. 1965. The web-spinning process and web-structure of Latrodectus tredecimguttatus, L. pallidus and L. revivensis. Proceedings of the Zoological Society of London 145:75-89.

Szlep, R. 1968. The web structure of Latrodectus variolus Walckener and L. bishopi Kaston. Israel Journal of Zoology 15:89-94.

Wenzel, J.W. 1993. Application of the biogenetic law to behavioral ontogeny: a test using nest architecture in paper wasps. Journal of Evolutionary Biology 6:229-247.

Manuscript received 23 January 2010, revised 12 August 2010. 